\title{
STRONG RECIPROCITY, HUMAN COOPERATION, AND THE ENFORCEMENT OF SOCIAL NORMS
}

\author{
Ernst Fehr, Urs Fischbacher \\ University of Zürich
}

and

\author{
Simon Gächter \\ University of St. Gallen
}

This paper provides strong evidence challenging the self-interest assumption that dominates the behavioral sciences and much evolutionary thinking. The evidence indicates that many people have a tendency to voluntarily cooperate, if treated fairly, and to punish noncooperators. We call this behavioral propensity "strong reciprocity" and show empirically that it can lead to almost universal cooperation in circumstances in which purely self-interested behavior would cause a complete breakdown of cooperation. In addition, we show that people are willing to punish those who behaved unfairly towards a third person or who defected in a Prisoner's Dilemma game with a third person. This suggests that strong reciprocity is a powerful device for the en forcement of social norms involving, for example, food sharing or collective action. Strong reciprocity cannot be rationalized as an adaptive trait by the leading evolutionary theories of human cooperation (in other words, kin selection, reciprocal altruism, indirect reciprocity, and costly signaling theory). However, multilevel selection theories of cultural evolution are consistent with strong reciprocity.

KEY WORDS: Evolution; Game theory; Human cooperation; Punishment; Social norms; Strong reciprocity

A key fact about human society is the ubiquity of material incentives to cheat on implicit or explicit cooperative agreements. In any kind of social

Received December 18, 2000; accepted March 19, 2001.

Address all correspondence to Prof. Dr. Ernst Fehr, Institute for Empirical Research in Economics, University of Zürich, Blümlisalpstr. 10, CH-8006 Zürich, Switzerland. E-mail: efehr@iezv.unizh.ch

Copyright 2002 by Walter de Gruyter, Inc., New York

Human Nature, Vol. 13, No. 1, pp. 1-25.

$1045-6767 / 02 / \$ 1.00+.10$ 
or economic exchange situation between two or more individuals in which not all aspects of the exchange are determined by enforceable contracts, there are material incentives to cheat. Even in modern human societies with a large cooperative infrastructure in the form of laws, impartial courts, and the police, the material incentive to cheat on cooperative agreements is probably the rule rather than the exception. This is so because, in general, not all obligations that arise in the various contingencies of exchange situations can be unambiguously formulated and subjected to a binding contract. ${ }^{1}$ Therefore, by reneging on the implicit or unenforceable obligations a party can always improve its material payoff relative to a situation in which it meets its obligations. Of course, in premodern societies lacking a cooperative infrastructure, cheating incentives are even more prevalent. It is probably true that in more than $90 \%$ of human history no cooperative infrastructure existed.

Another key fact about human society is that, despite these incentives to cheat, many "nonbinding" agreements among non-kin occur and are kept. Since cooperation regularly also takes place among non-kin, genetical kinship theory (Hamilton 1964) cannot readily account for this fact. One possibility to account for the manifest cooperation among non-kin is to recognize that many social interactions take place repeatedly. Evolutionary theorists, for example, have shown that natural selection can favor reciprocally cooperative behavior in bilateral interactions when the chances to interact repeatedly with the same individual in the future are sufficiently high (Axelrod and Hamilton 1981; Trivers 1971). Since cheating (i.e., not reciprocating a cooperative act) can be deterred by the withdrawal of future cooperation, it is in the long-run interest of organisms not to cheat. Therefore, in bilateral repeated interactions reciprocal cooperation can be an evolutionarily stable outcome. In a similar spirit, game theorists have shown that, when the chances for repeated interactions are sufficiently high, rational egoists (i.e., rational actors who are solely interested in their own material well-being) can establish an equilibrium with full cooperation despite the existence of short-run cheating incentives (Friedman 1971; Fudenberg and Maskin 1986). Not only does cheating have short-run benefits, it may also have longrun costs depending on the nature of the equilibrium that is played. In a cooperative equilibrium the implicit or explicit threat to withdraw future cooperation from cheaters deters cheating, and as a consequence, cooperation can be sustained by self-interested, rational actors. However, in multilateral $n$-person interactions, which are typical for human societies, the prospects for sustaining cooperation in an evolutionary equilibrium by individual threats of withdrawing future cooperation are quite limited. Boyd and Richerson (1988) have shown that for reason- 
able group sizes this mechanism for sustaining cooperation does not work.

In this paper we provide strong evidence in favor of another, distinct, cooperation-enhancing force that has thus far been largely neglected. We call this force strong reciprocity (see also Bowles and Gintis 2001; Gintis 2000). A person is a strong reciprocator if she is willing to sacrifice resources $(a)$ to be kind to those who are being kind (strong positive reciprocity) and (b) to punish those who are being unkind (strong negative reciprocity). The essential feature of strong reciprocity is a willingness to sacrifice resources for rewarding fair and punishing unfair behavior even if this is costly and provides neither present nor future material rewards for the reciprocator. Whether an action is perceived as fair or unfair depends on the distributional consequences of the action relative to a neutral reference action (Rabin 1993). We will show that many people exhibit strong reciprocity, and their existence greatly improves the prospects for cooperation. We provide evidence that strong reciprocity can give rise to almost maximal cooperation in circumstances in which the standard repeated interaction approach predicts no cooperation at all. However, we also provide evidence indicating that there are social structures in which the interaction between strong reciprocators and purely selfish persons induces the majority of people to cheat. This highlights the importance of social structures for the achievement of stable cooperation. In addition, we show that strong reciprocity is also a powerful norm-enforcement device. Therefore, strong reciprocity may help explain the enforcement of food-sharing norms and norms that prescribe participation in collective actions.

It is important to distinguish strong reciprocity from terms like "reciprocal altruism" and "altruism." An altruistic actor is unconditionally kindin other words, the kindness of her behavior does not depend on the other actor's behavior. A reciprocally altruistic actor, in contrast, conditions her behavior on the previous behavior of the other actor. Yet, while a reciprocally altruistic actor is willing to incur short-run costs to help another actor, she does this only because she expects long-term net benefits. The distinction among strong reciprocity, altruism, and reciprocal altruism can most easily be illustrated in the context of a sequential Prisoner's Dilemma (PD) that is played exactly once. In a sequential PD, player A first decides whether to defect or to cooperate. Then player B observes player A's action, after which she decides to defect or to cooperate. To be specific, let the material payoffs for $(A, B)$ be $(5,5)$ if both cooperate, $(2,2)$ if both defect, $(0,7)$ if A cooperates and B defects, and $(7,0)$ if A defects and B cooperates. If player $B$ is an altruist she never defects even if player A defected. Altruism, as we define it here, is thus tantamount to unconditional kindness. In 
contrast, if player B is a strong reciprocator she defects if $A$ defected and cooperates if A cooperated because she is willing to sacrifice resources to reward a behavior that is perceived as kind. A cooperative act by player $\mathrm{A}$, despite the material incentive to cheat, is a prime example of such kindness. The kindness of a strong reciprocator is thus conditional on the perceived kindness of the other player. Reciprocal altruism, as it is frequently used in evolutionary biology, also differs fundamentally from strong reciprocity because a reciprocal altruist only cooperates if there are future returns from cooperation. Thus a reciprocally altruistic player B will always defect in a sequential one-shot PD. Since a reciprocal altruist performs altruistic actions only if the total material returns exceed the total material costs, we do not use this term in the rest of the paper. Instead, we use the term "selfish" for this motivation.

\section{EVOLUTIONARY THEORY AND STRONG RECIPROCITY}

The fact that many people retaliate or cooperate when it is costly and provides no material rewards raises the question of why people behave in this way. We believe that the answer to this question ultimately must be sought in the evolutionary conditions of the human species that caused a propensity for strongly reciprocal behavior among a significant fraction of the population. Our evidence suggests that strong reciprocity cannot be explained by the motives that are typically invoked by the major prevailing evolutionary theories of altruism and cooperation. We will argue that our evidence is incompatible with the typical motives invoked by kin selection theory (Hamilton 1964), by reciprocal altruism theory (Axelrod and Hamilton 1981; Trivers 1971), by the theory of indirect reciprocity (Alexander 1987; Nowak and Sigmund 1998), and by costly signaling theory (Gintis et al. 2001; Zahavi and Zahavi 1997). The puzzling question to be solved by evolutionary theory is, therefore, how strong reciprocity could survive in human evolution. This question is important because-as our experiments show-the presence of strong reciprocators greatly increases and stabilizes human cooperation.

Since our claim that major evolutionary theories of altruism and cooperation cannot readily account for strong reciprocity is quite provocative, it is worthwhile to explain exactly what we mean in order to prevent any misunderstanding. Our argument is that the observed experimental behaviors cannot be rationalized as adaptive behaviors by these evolutionary models. This means that if one assumes the conditions of the experiment (in particular, that strangers interact anonymously with each other in one-shot situations), these theories predict that strongly reciprocal behavior cannot prevail in an evolutionary equilibrium. Or put differently, 
from the viewpoint of these theories the observed experimental behaviors and the underlying motives must be classified as maladaptive. In view of the robustness and the frequency of strong reciprocity across many different cultures (see, e.g., Henrich et al. 2001) this seems quite unsatisfactory. Particularly problematic is the argument that experimental subjects are not capable of distinguishing between repeated interactions and one-shot interactions. As a consequence, so the maladaptation story goes, subjects tend to inappropriately apply heuristics and habits in experimental oneshot interactions (i.e., they take revenge or they reward helping behavior) that are only adaptive in a repeated interaction context but not in a oneshot context. In the final part of the paper, where we discuss the proximate mechanisms behind strong reciprocity, we show that this argument is refuted by the data. The evidence suggests that subjects are well aware of the difference between one-shot and repeated interactions because they behave quite differently in these two conditions.

Recently, Gintis (2000) developed an evolutionary model of strong reciprocity. $^{2}$ His model is based on the plausible idea that in the relevant evolutionary environment human groups faced extinction threats (wars, famines, environmental catastrophes). When groups face such extinction threats neither reciprocal altruism nor indirect reciprocity can sustain the necessary cooperation that helps the groups to survive the situation because the shadow of the future is too weak. Kin-selection also does not work here because in most human groups membership is not restricted to relatives but is also open to non-kin members. However, groups with a disproportionate number of strong reciprocators are much better able to survive these threats. Hence, within-group selection creates evolutionary pressures against strong reciprocity because strong reciprocators engage in individually costly behaviors that benefit the whole group. In contrast, between-group selection favors strong reciprocity because groups with disproportionately many strong reciprocators are better able to survive. The consequence of these two evolutionary forces is that in equilibrium strong reciprocators and purely selfish humans coexist. Another model that is capable of explaining punishment in one-shot situations is the cultural evolutionary model of Henrich and Boyd (2001), which is based on the notion of conformist transmission. Henrich and Boyd show that even a very small amount of conformist transmission can stabilize one-shot punishments in an evolutionary equilibrium. Multilevel selection theories only provide plausible ultimate explanations of human altruism, however, if they are interpreted in terms of cultural evolution rather than genetic evolution (Soltis et al. 1995) because cultural variation between groups is much bigger than the genetic variation between groups. Multilevel selection theories of altruism, such as the one by Sober and Wilson (1998), are also compatible with strong reciprocity. 


\section{EVIDENCE AND CONSEQUENCES OF STRONG RECIPROCITY}

\section{The Enforcement of "Nonbinding" Agreements}

In many bilateral one-shot encounters in real life people behave in a reciprocally fair way. A good example is the exchange between a taxi driver and his passenger in a big city (Basu 1984). On the surface this example represents a trivial economic exchange. A closer look, however, shows that this exchange frequently is similar to a sequentially played one-shot PD because the probability of repeated interactions is extremely low and the taxi driver first has to decide whether to cooperate (drive) or not. Once the taxi driver has provided his service, it would often be quite easy for the passenger to escape without paying unless the passenger expects that the taxi driver will incur the cost of chasing him. Yet for the taxi driver the cost of chasing a nonpaying passenger would typically be much higher than the return. In these situations a selfish taxi driver will never chase the passenger. Thus, if all taxi drivers were purely selfish, passengers could often escape without paying the bill. This example shows that even in seemingly trivial exchanges the enforcement of the obligation of at least one party is often not guaranteed so that the contract is in an important sense incomplete. However, despite the incentive to leave without paying, most passengers reciprocate the service by paying the bill. In our view there are two major reasons for this: (a) Many people are indeed inclined to exhibit strong positive reciprocity, i.e., they pay the bill even if they could escape at low cost without paying. (b) Many taxi drivers would be extremely upset if the passenger tried to go away without paying and, as a consequence, they would be willing to bear considerable costs to catch and punish the cheater. Therefore, if potential cheaters anticipate this, most of them are probably better off by not cheating. This example indicates how the combined effects of strong positive and negative reciprocity contribute to the enforcement of sequential exchanges that are beneficial for both parties.

In addition to real world examples, there also is evidence for strong reciprocity between anonymously interacting trading partners from wellcontrolled laboratory experiments (Berg et al. 1995; Fehr, Kirchsteiger, and Riedl 1993, 1998). ${ }^{3}$ In these experiments subjects can earn money according to their decisions and the rules of the experiment. To preserve the oneshot character of the experiment subjects were never informed about the identity of their exchange partner. Moreover, experimental procedures also ensured that no individual subject could ever gain a reputation for being, for example, cooperative. Exchange partners were located in different rooms. These features of the experiment ensured that the exchange really took place between anonymous strangers. In the following discussion we illustrate the regularities of strongly reciprocal behavior on the basis of 
one of these experiments conducted at the University of Zurich (Fehr, Gächter, and Kirchsteiger 1997).

In the experiment a subject in the role of an employer (or buyer) can make a job offer (or contract for one unit of a good) to the group of subjects in the role of workers (or sellers). Each worker can potentially accept the offer. There are more workers than employers to induce competition among the workers. A job offer consists of a binding wage offer (or price offer: $w$ ) and a nonbinding "desired effort level" (or "desired quality level": $\hat{e})$. If one of the workers accepts an offer $(w, \hat{e})$ she has to determine the $a c$ tual effort level, $e$. In the experiment the choice of an effort level is represented by the choice of a number. The higher the chosen number, the higher is the effort and the higher are the monetary effort costs borne by the worker. The desired and the actual effort levels have to be in the interval $\left[e_{\text {min }}, e_{\text {max }}\right] \equiv[0.1,1]$ and the wage offer has to be in the interval $[0,100]$. The higher the $e$, the larger the material payoff for the employer but also the higher the costs, $c(e)$, of providing $e$ for the worker. Material payoffs from an exchange are given by $\Pi_{f}=100 e-w$ for the employer and $\Pi_{w}=w$ - $c(e)$ for the worker. A party who does not manage to trade earns zero. The effort costs are given in Table 1 . Note that since $\hat{e}$ is nonbinding the worker can choose any $e$ in the interval [0.1,1]; that is, she can also choose less than $\hat{e}$ without being sanctioned. Since effort costs are strictly increasing in $e$, a selfish worker will always choose $e=e_{\min }=0.1$. Therefore, a rational and selfish employer who believes that there are only selfish workers will never offer a wage above $w=1$. This employer knows that the workers will incur no effort costs and, being selfish, will accept a wage offer of $w=1$. At $w=1$ the trading worker earns $\Pi_{w}=1$, which is more than if the worker does not trade.

In sharp contrast to the predictions based on the selfishness assumption, we observe the following regularities: The vast majority of contract offers imply, if accepted and met, a much larger profit than $\Pi_{w}=1$ for the worker. On average the profit implied by the offer, which is defined by $w-c(\hat{e})$, is 35 units. Moreover, the higher the $\hat{e}$, the higher the profit, $w-c(\hat{e})$, offered to the worker (see Figure 1). This means that employers do not just compensate the workers for the higher effort costs, they increase the profit of the workers if they desire a higher effort level (i.e., they share the increase in the total returns that are created by higher effort levels). The employers appeal to the strong reciprocity of the workers by being more generous as

Table 1. Effort Levels and Costs of Effort

\begin{tabular}{lllllllllll}
\hline effort $(e)$ & 0.1 & 0.2 & 0.3 & 0.4 & 0.5 & 0.6 & 0.7 & 0.8 & 0.9 & 1 \\
costs of effort $c(e)$ & 0 & 1 & 2 & 4 & 6 & 8 & 10 & 12 & 15 & 18 \\
\hline
\end{tabular}




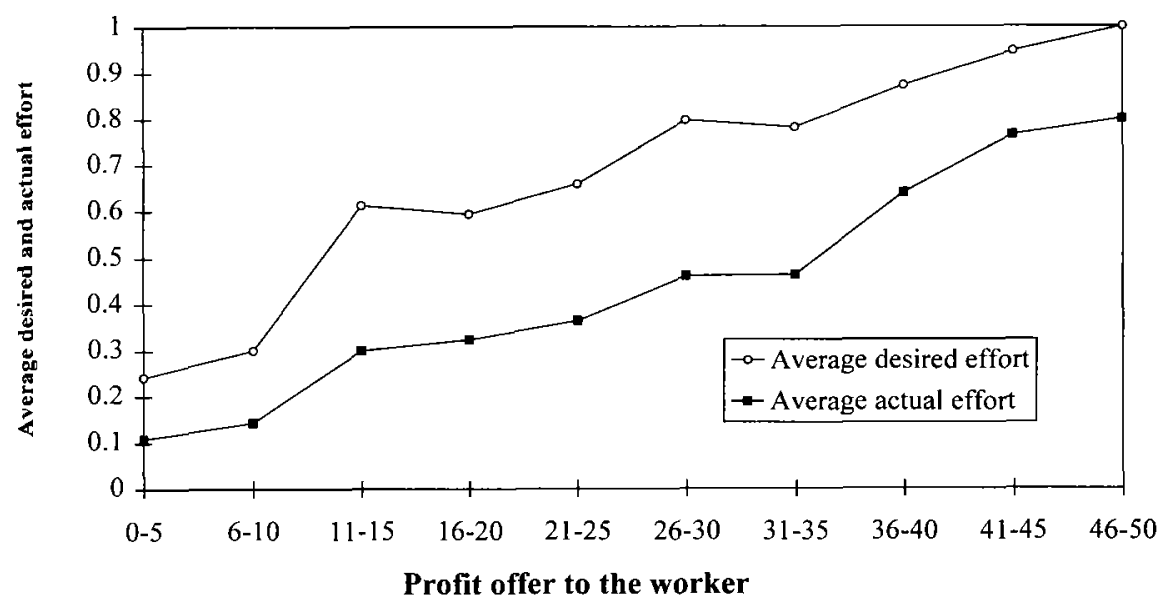

Figure 1. Relation of desired effort and actual effort to the profit offered to the worker.

the desired effort level becomes more costly to the worker. Workers, in turn, exhibit a considerable amount of strong reciprocity (Figure 1). Although the actual average effort is below the desired average effort, it is, in general, clearly above $e_{\min }$. Moreover, there is a strong positive correlation between the generosity of the offer, in other words, the level of $w$ $c(\hat{e})$, and the actual average effort.

The results depicted in Figure 1 indicate that on average the subjects have a propensity for strong positive reciprocity. However, the average can be somewhat misleading because it hides the presence of purely selfish subjects. In addition to the studies cited above there are by now also several other studies indicating that subjects are heterogeneous with regard to their propensity to exhibit strong reciprocity (Abbink et al. 2000; Bolle 1998; Charness 2000; Fehr and Falk 1999; Gächter and Falk 2001; McCabe et al. 1998, 2000). As in the above experiment, subjects in these studies always interact anonymously with each other and reciprocal behavior is costly in terms of real money for the reciprocator. Taken together, the fraction of subjects showing strong positive reciprocity is rarely below $40 \%$ and sometimes $60 \%$ while the fraction of selfish subjects is also often between $40 \%$ and $60 \%$. Moreover, these frequencies of strong positive reciprocity are observed in such diverse countries as Austria, Germany, Hungary, the Netherlands, Switzerland, Russia, and the U.S. It is also worthwhile to stress that strong positive reciprocity is not diminished if the monetary stake size is rather high. In the experiments conducted by Fehr and Tougareva (1995) in Moscow, subjects earned on average the monetary in- 
come of ten weeks in an experiment that lasted for two hours. The monthly median income of subjects was US \$17 whereas in the experiment they earned on average US $\$ 45$. The impact of strong reciprocity also does not vanish if the experimental design ensures that the experimenter cannot observe individual decisions but only aggregate decisions (Abbink et al. 2000; Berg et al. 1995; Bolton and Zwick 1995).

In an extension of the above experiment we examined the impact of giving the employers the option of responding reciprocally to the worker's choice of $e$. We achieved this by giving the employer the opportunity to reward or punish the worker after she observes the actual effort. ${ }^{4}$ By spending one experimental money unit (MU) on reward the employer could increase the worker's payoff by $2.5 \mathrm{MU}$, and by spending $1 \mathrm{MU}$ on punishment the employer could decrease the worker's payoff by $2.5 \mathrm{MU}$. Employers could spend up to $10 \mathrm{MU}$ on punishment or on rewarding their worker. The important feature of this design is that if there are only selfish employers they will never reward or punish a worker because both rewarding and punishing are costly for the employer. Therefore, if there are only selfish employers, the workers' decisions should be the same irrespective of whether or not there is an opportunity for rewarding and punishing. However, if a worker expects her employer to be a strong reciprocator it is likely she will provide higher effort levels in the presence of a reward/punishment opportunity. This is so because strongly reciprocal employers are likely to reward the provision $(e=\hat{e})$ or the overprovision $(e>\hat{e})$ of effort and to punish the underprovision $(e<\hat{e})$. This is in fact exactly what one observes, on average. If there is underprovision of effort employers punish in $68 \%$ of the cases and the average investment in punishment is $7 \mathrm{MU}$. If there is overprovision employers reward in $70 \%$ of these cases and the average investment in rewarding is also $7 \mathrm{MU}$. If workers exactly meet the desired effort employers still reward in $41 \%$ of the cases and the average investment in rewarding is $4.5 \mathrm{MU}$.

We also elicited workers' expectations about the reward and punishment choices of their employers. Hence, we are able to check whether workers anticipate employers' strong reciprocity. It turns out that in cases of underprovision workers expect to be punished $54 \%$ of the time and the average expected punishment is $4 \mathrm{MU}$. In case of overprovision they expect to receive a reward in $98 \%$ of the cases with an expected average investment of 6.5 MU. As a result of these expectations, workers choose much higher effort levels when employers have a reward/punishment opportunity. The presence of this opportunity decreases underprovision from $83 \%$ to $26 \%$ of the trades, increases exact provision of $\hat{e}$ from $14 \%$ to $36 \%$, and increases overprovision from $3 \%$ to $38 \%$. The average effort level is increased from $e=0.37$ to $e=0.65$ so the gap between desired and actual effort levels almost vanishes. An important consequence of this increase in average effort is that 
the aggregate monetary payoff increases by $40 \%$-ven if one takes the payoff reductions that result from actual punishments into account. Thus, the reward/punishment opportunity considerably increases the total pie that becomes available for the trading parties.

The evidence presented above confirms that strong reciprocity substantially contributes to the enforcement of cooperative agreements in bilateral sequential exchanges. The power of strong reciprocity derives from the fact that it provides incentives for potential cheaters to behave cooperatively or at least to limit their degree of noncooperation. In the above experiments, for example, even purely selfish employers have an incentive to make a cooperative first move (i.e., to make a generous job offer) if they expect a sufficient number of workers to behave in a strongly reciprocal manner. Similarly, even purely selfish workers have an incentive to provide a high level of effort in case of a reward/punishment opportunity if they expect employers to be strong reciprocators.

Note that the strongly reciprocal behavior in the previous experiments cannot be explained by the major prevailing theories of altruism and cooperation. Since subjects know that they are strangers to each other, kin selection theory does not apply. Since the interaction is one-shot, there are no future material rewards from present cooperation or retaliation so that reciprocal altruism theory does not apply either. Since subjects interact anonymously with each other and, hence, can develop no individual reputation for being cooperative or retaliatory, the theory of indirect reciprocity does not apply. Finally, anonymity also ensures that cooperation cannot be used as a costly signal for unobservable traits-in other words, costly signaling theory does not apply either. It is worthwhile to stress that the same arguments can be made with regard to the other experiments discussed in this paper. Because in these experiments strangers interacted with each other just once, and anonymously, the major prevailing evolutionary theories cannot rationalize the observed experimental behaviors.

\section{Punishment in Bilateral Bargaining Situations}

There are many real-life examples of the desire to take revenge and to retaliate in response to harmful and unfair acts. One important example is that people frequently break off bargaining with opponents that try to squeeze them. This can be nicely illustrated by so-called ultimatum bargaining experiments (Camerer and Thaler 1995; Güth et al. 1982; Roth 1995). In the ultimatum game two subjects have to agree on the division of a fixed sum of money. Person A, the Proposer, can make exactly one proposal of how to divide the amount. Then person B, the Responder, can accept or reject the proposed division. In the case of rejection both receive nothing, whereas in the case of acceptance the proposal is implemented. 
This experiment has yielded robust results indicating that proposals giving the Responder less than $20 \%$ of the available sum are rejected with a very high probability. This shows that Responders do not behave in a selfinterest-maximizing manner. In general, the motive indicated for the rejection of positive, yet "low," offers is that subjects view them as unfair. As in the case of positive reciprocity, strong negative reciprocity is observed in a wide variety of cultures, and rather high monetary stakes either do not change or have only a minor impact on these experimental results. By now there are literally hundreds of studies of one-shot ultimatum games. Rejections of positive offers are observed in Israel, Japan, many European countries, Russia, Indonesia, and the U.S. For an early comparison across countries see Roth and colleagues (1991). Cameron's (1999) study with Indonesian subjects offered to divide the equivalent of three months' income. Other studies with relatively high stakes include that of Hoffman, McCabe, and Smith (1996), which involved US $\$ 100$ to be divided by U.S. students, and that of Slonim and Roth (1998).

\section{Multilateral Cooperation and Punishment Opportunities}

The previously discussed studies involve bilateral relations. In view of the ubiquity of $n$-person interactions in human evolution and everyday life, however, it is important to know how people behave in $n$-person situations. One question that is particularly important is how the selfish types and the strongly reciprocal types affect one another in these situations. What are the interaction structures that enable the selfish types to induce the strong reciprocators to behave noncooperatively, and what are the structures that enable the strong reciprocators to force or induce the selfish types to behave cooperatively? In view of the fact that strong reciprocators are willing to punish unfair behavior, it seems likely that the presence or absence of punishment opportunities is crucial here. To illustrate the argument, consider the example of a simultaneously played one-shot PD, in which a purely selfish subject is matched with a strong reciprocator. If the reciprocal subject knows that she faces a selfish subject, she will defect because she knows that the selfish subject will always defect. Consider now a slightly different game in which both players have the opportunity to punish the other player after they could observe the other player's action. Assume further that the punishment is costly for the punisher, which ensures that a purely selfish subject will never punish. In contrast, a cooperating strong reciprocator is willing to punish a defecting subject because the defection is likely to be viewed as very unfair. Therefore, if the selfish subject anticipates that a defection will be punished, she has an incentive to cooperate. This suggests that in the presence of punishment opportunities strong reciprocators can force the selfish types to cooperate, whereas in the 
absence of punishment opportunities the selfish types induce the reciprocal types to defect, too. This argument has been generalized and rigorously proven by Fehr and Schmidt (1999), who show that in an $n$-person public goods game with a heterogeneous population of players, full defection by everybody is likely to be the unique equilibrium in the game without punishment while full cooperation can be an equilibrium in the game with punishment.

The following public goods game, which is essentially a generalized $n$-person PD, has been used to examine the empirical validity of this conjecture (Fehr and Gächter 2000, 2002). In a group of four anonymously interacting subjects each subject is endowed with 20 tokens. Subjects decide simultaneously how many tokens to keep for themselves and how many tokens to invest in a common project. For each token that is privately kept a subject earns exactly one token. Yet, for each token a subject invests into the project each of the four subjects earns 0.4 tokens. Thus, the overall private return for investing one additional token into the project is $-1+0.4=$ -0.6 tokens while the overall social return is $-1+4(0.4)=+0.6$ tokens. This means that, irrespective of how much the other three subjects contribute to the project, it is always better for a subject to keep all tokens privately. Therefore, if all subjects are purely selfish they will all keep all their tokens privately. Yet, if all fully defect, i.e., keep all their tokens privately, each earns only 20 tokens, whereas if all invest their total token endowment, each subject earns $0.4(80)=32$ tokens. In the no-punishment condition the same group of subjects plays this game for ten periods. At the end of each period they are informed about the contributions of the other three group members. In the punishment condition subjects also play the game for ten periods. In addition to their investment decision, they can also assign punishment points to each of the other group members at the end of each period, after they have been informed about the others' contributions. The costs of punishment for the punisher are a convex and increasing function of the total number of punishment points assigned to the others. Each subject can assign up to ten punishment points to each of the other group members. Assigning ten points to another member costs the punisher 30 tokens; assigning no points costs the punisher nothing; and assigning an intermediate amount of punishment points costs an intermediate amount of tokens. For each received punishment point the monetary income of the punished subject is reduced by $10 \%$. A reduction of $10 \%$ implies, on average, an income reduction between 2 and 3 tokens. The experiment ensures that group members cannot trace the history of individual investments or individual punishments of a particular subject in a group. It is therefore impossible to gain an individual reputation for being (non)cooperative or for being a punisher.

Fehr and Gächter (2000) also conducted punishment and no-punishment conditions in which the group composition was randomly changed 
in each of the ten periods. In these experiments there is a large group of 24 people and in each of the ten periods new four-person groups are randomly formed. When the group composition is random in every period the probability of meeting the same group members again in future periods is very small. Moreover, even if subjects have already encountered some of the group members in one of the previous periods, they have no way of identifying the other members in the group. Thus, the random group design essentially constitutes a situation in which strangers anonymously interact in a series of one-shot games.

In the random group design the predictions are quite straightforward if all subjects are selfish and are known to be selfish. Since in each period the group members essentially play a one-shot game the subjects will never punish because punishment is costly for them and yields no future benefits. While punishment might increase the cooperation of the punished subject in future periods, for the punisher the probability of gaining from this is very low due to the low probability of meeting the punished group member again. Therefore, punishing other subjects makes no sense for a selfish individual. Yet, if there is no punishment it also makes no sense for a selfish subject to cooperate because any form of cooperation causes a reduction in the material payoff to the cooperating subject. Thus, both in the punishment condition as well as in the no-punishment condition of the random group design no cooperation should occur if all subjects are purely selfish. However, if the selfish subjects expect the presence of strong reciprocators in the group (i.e., if they expect to be punished in case of free-riding), the selfish types have an incentive to cooperate. Hence, in the presence of strong reciprocators we expect quite different cooperation levels across the punishment and the no-punishment condition. In particular, we expect less cooperation in the no-punishment design.

The same predictions hold for the stable group design as for the random group design if it is common knowledge that all subjects are rational and selfish money-maximizers. In fact, under this assumption, we should observe exactly the same investment behavior in both the punishment and the nopunishment condition, namely, no investment at all in all periods. The no-investment prediction is most transparent for period ten. Since all subjects know that the experiment ends in period ten their best private choice in the no-punishment condition is to invest nothing. In the punishment condition their best choice at the punishment stage in period ten is not to punish at all because punishment is costly. Yet, since rational egoists anticipate that nobody will punish, the presence of the punishment stage does not change the behavioral incentives at the investment stage of period ten. Therefore, in the punishment condition also nobody will invest in period ten. Since rational egoists will anticipate this outcome for period ten, they know that their actions in period nine do not affect the decisions in period ten. Therefore, punishing in period nine makes no sense for selfish players 
and, as a consequence, full defection at the investment stage of period nine is again their best choice. This backward induction argument can be repeated until period one so that full defection and no punishment is predicted to occur for all ten periods of the punishment treatment. The same backward induction logic also, of course, predicts defection in all periods of the no-punishment treatment. 5

The presence of strong reciprocators will again change the predictions substantially because if a subject is punished for free-riding in period $t<$ 10 , he or she knows for sure that the punisher is also part of the group in the next period. Hence, the punished subject has a much stronger incentive to cooperate in the stable group design compared to the random group design. As a consequence, cooperation rates should be higher in the stable group design compared to the random group design.

In sharp contrast to the prediction of zero punishment, subjects punish very often in both the stable group design and the random group design. Figure 2 illustrates the punishment behavior in both designs. It depicts the average punishment imposed on a player as a function of the deviation of the investment of the punished player from the average investment of the other group members. The numbers above the bars denote the relative frequency of observations that correspond to each bar. The stable group design is denoted "Partner" design and the random group design is denoted "Stranger" design. Remarkably, the strength of the punishment is almost as high in the Stranger design as in the Partner design. For example, if a group member invests between 14 and 8 tokens less than the other group members, his income is reduced by roughly 55\% in the Partner design and

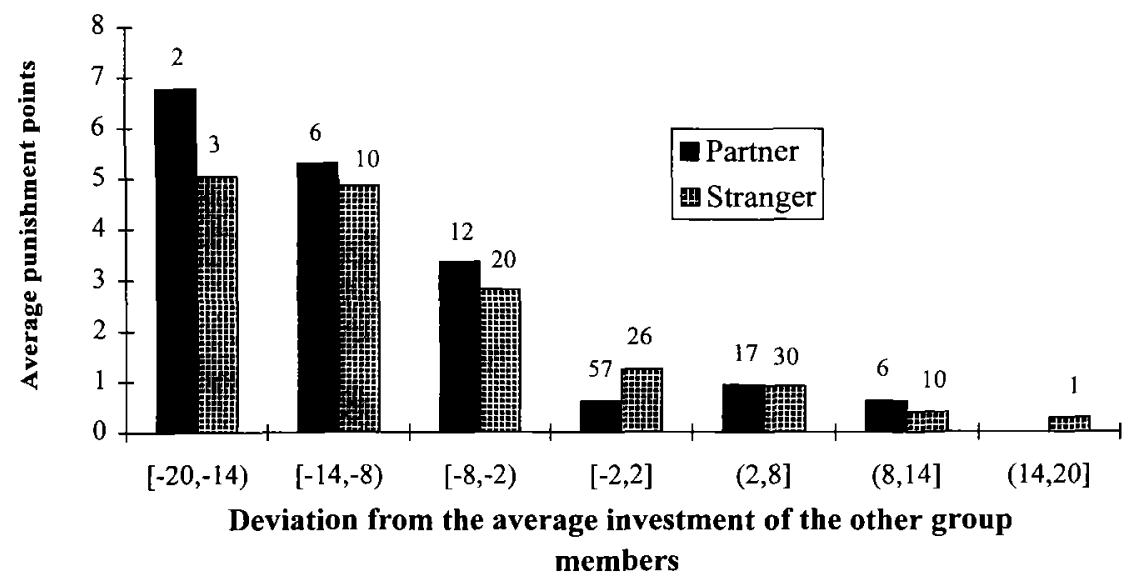

Figure 2. Punishment received as a function of the deviation from others' average investment (10 partner groups, 18 stranger groups). 
by $50 \%$ in the Stranger design. Moreover, punishment follows a clear pattern. The large majority of punishments are imposed on the defectors and executed by the cooperators. The punishment imposed on a subject increases the more the subject's contribution falls short of the average contribution of the other three group members. The positive relation between received punishment and the negative deviation from others' contributions is highly significant, whereas there is no relation between positive deviations and the received punishment. Note that the punishment of below-average investments also prevails in period ten.

What is the impact of this punishment pattern on investment behavior? It turns out that contribution rates differ dramatically between the two conditions. Figure 3 shows the time trend of average investments in the stable group design and Figure 4 shows the trend in the random group design. Note that in both designs the same subjects first participated in the no-punishment condition and then they participated in the punishment condition. Fehr and Gächter (2000) also reversed the order in which subjects participated in the two designs. The results are almost identical to the results shown in Figures 3 and 4. A remarkable feature of Figures 3 and 4 is that in both designs cooperation breaks down in the no-punishment condition. Initially cooperation is relatively high but over time it unravels, and in the final period the absolute majority of the subjects invest nothing and the rest of the subjects invest very little. This supports our view that in the absence of an explicit punishment opportunity the selfish types induce the reciprocal types to behave noncooperatively, too. Noncooperation is the only way in which the reciprocal types can at least implicitly

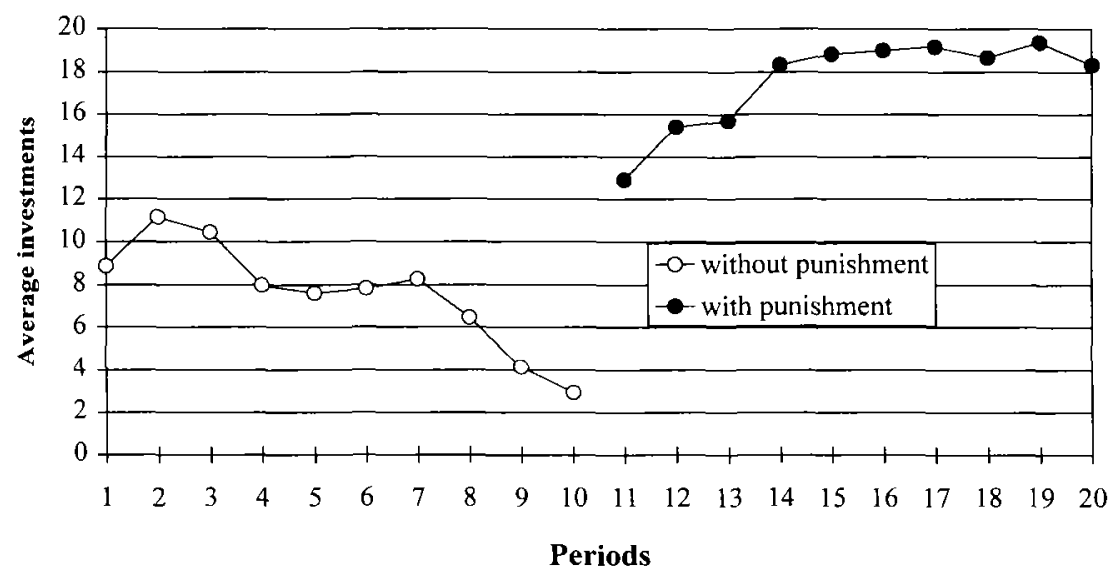

Figure 3. Average investments over time in public good games with stable groups (10 groups). 


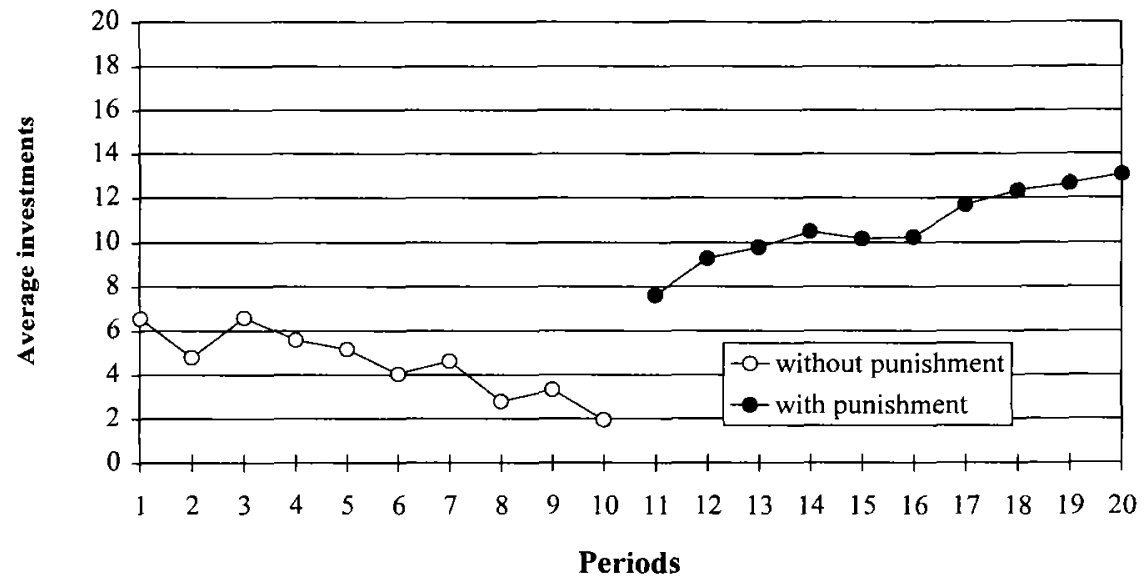

Figure 4. Average investments over time in public good games with random groups (18 groups).

punish the defectors in their groups. However, if the strong reciprocators are given the opportunity to target their punishments directly at the individual defectors, the pattern of cooperation is very different. In both the stable and the random group designs, average investments even increase over time. In the stable group design the increase in average investments is much larger, and eventually almost full cooperation is achieved.

The very high cooperation in the punishment conditions represents an unambiguous rejection of the standard repeated interaction approach but is consistent with the strong reciprocity approach. Moreover, the substantial difference in cooperation rates across punishment and no-punishment conditions indeed suggests that in the presence of punishment opportunities the strong reciprocators can force the selfish types to cooperate whereas in the absence of such opportunities the selfish types induce the strong reciprocators to defect. Thus, interaction structures that have theoretically identical implications if there are only selfish types generate fundamentally different behavioral patterns in the presence of strong reciprocators.

\section{Strong Reciprocity as a Norm Enforcement Device}

Many small-scale societies are characterized by extensive food sharing. A simple game to examine whether food sharing is a social norm that is enforced by social sanctions has been conducted by Fehr and Fischbacher (2001a). The game is called "third-party punishment game" and has three players. The game between player A and player B is just a dictator game. Player A receives an endowment of 100 tokens of which he can transfer 
any amount to player B, the Recipient. Player B has no endowment and no choice to make. Player $C$ has an endowment of 50 tokens and observes the transfer of player A. After this player $C$ can assign punishment points to player A. For each punishment point assigned to player $A$, player $C$ has costs of 1 token and player A has costs of 3 tokens. Since punishment is costly, a self-interested player $C$ will never punish. However, if there is a sharing norm, player $C$ may well punish player $A$ if he gives too little.

In fact, in the above experiments player $A$ is never punished if he transfers 50 or more tokens to player B. The less player A transfers (under 50), the stronger the punishment he receives. When player A transferred nothing, he received on average 9 punishment points from player $C$ (i.e., the payoff of player A was reduced by 27 tokens). Hence, in this three-person game it was still more beneficial, from a selfish point of view, for player $A$ to give nothing than to make an equal split. If there is more than one player $C$, and each can punish player $A$, this may no longer be the case.

Another interesting question is to what extent cooperation norms are sustained through the punishment of free-riders by third parties. We have already seen in the public goods experiment with punishment that strikingly high cooperation rates can be enforced through punishment. In this game each investment (i.e., contribution to the public good) increases the payoff of each group member by 0.4 . Thus, if a group member free-rides instead of cooperating she directly reduces the other group members' payoffs. In real life there are, however, many situations in which free-riding has a very low, indeed almost imperceptible, impact on the payoff of certain other individuals. The question then is whether these individuals will nevertheless help enforce a social norm of cooperation. If they do, society's capability of enforcing social norms is greatly magnified because each member of a society acts as a potential "policeman."

It is relatively easy to construct cooperation games with punishment opportunities for third (unaffected) parties. Fehr and Fischbacher (2001a), for example, have conducted PDs in which one player of a two-person PD game observes and can punish a member of some other group who also played the PD. Thus, each member could punish and could be punished by someone outside their own two-person group. Reciprocal punishment was not possible- -in other words, if subject A could punish subject B, subject $B$ could not punish $A$ but only some third subject $C$. The punishment by third parties turns out to be surprisingly strong. It is only slightly weaker than second-party (within-group) punishment.

\section{Proximate Mechanisms behind Strong Reciprocity}

Within economics, the leading explanation for the patterns of results described above is that agents have social preferences (or "social utility") which take into account the payoffs and perhaps intentions of others. 
Roughly speaking, social preference theories assume that people have preferences for how money is allocated (which may depend on whom the other player is, or how the allocation came about). From a theoretical viewpoint such preferences are not fundamentally different from preferences for food, the present versus the future, how close one's house is to work, and so forth. In recent years several theories of social preferences have been developed (Bolton and Ockenfels 2000; Charness and Rabin 2000; Dufwenberg and Kirchsteiger 1998; Falk and Fischbacher 1999; Fehr and Schmidt 1999; Levine 1998; Rabin 1993). Some of these theories are capable of correctly predicting the bulk of the previously described evidence. For example, the theories of Falk and Fischbacher (1999) and Fehr and Schmidt (1999) predict that positive and negative reciprocity help enforce nonbonding agreements, that negative reciprocity leads to the rejection of very unequal offers in the ultimatum game, that free-riders are punished in $n$-person cooperation games, and that third parties punish low transfers in the dictator game and defection in other groups in the PD. ${ }^{6}$

It is important to stress that social preference theories only capture proximate mechanisms driving the observed behaviors. They do not aim at explaining the ultimate sources of strong reciprocity. Cultural anthropologists and evolutionary psychologists have sought to explain the origin of strong reciprocity. One idea is that in the environment of evolutionary adaptation (EEA) or ancestral past, people mostly engaged in repeated games with people they knew. Evolution created specialized cognitive heuristics for playing repeated games efficiently. It is well-known in game theory that behavior which is optimal for a self-interested actor in a oneperiod game with a stranger-such as defecting or free riding, and accepting all ultimatum offers-is not always optimal in repeated games with partners. In a repeated ultimatum game, for example, it pays to reject offers to build up a reputation for being hard to push around, which leads to more generous offers in the future. In the unnatural habitat view, subjects cannot "turn off" the habitual behavior shaped by repeated-game life in the EEA when they play single games with strangers in the lab.

The unnatural habitat theory assumes the absence of a module or cognitive heuristic which could have evolved but did not-the capacity to distinguish temporary one-shot play from repeated play. If subjects had this ability, they would behave appropriately in the one-shot game. In principle it is testable whether people have the ability to distinguish temporary oneshot play from repeated play. For example, Fehr and Gächter (2000) show that cooperation rates are generally lower in public good games when the group composition changes randomly in every period than they are when the group composition is constant across all ten periods. This fact suggests that, on average, subjects can distinguish between one-shot and repeated interactions because when the group composition changes randomly the 
probability of meeting the same people again in future periods is much lower. However, a fully satisfactory test of subjects' capacity to distinguish one-shot from repeated interactions requires that the same subjects participate in both conditions so that we can examine behavioral changes across conditions at the individual level. Fehr and Fischbacher (2001b) did this in the context of the ultimatum game.

Fehr and Fischbacher conducted a series of ten ultimatum games under two different conditions. In both conditions subjects played against a different opponent in each of the ten periods of the game. In each period of the baseline condition the Proposers knew nothing about the past behavior of their current Responders. Thus, the Responders could not build up a reputation for being "tough" in this condition. In contrast, in the reputation condition the Proposers knew the full history of the behavior of their current Responders-in other words, the Responders could build up a reputation for being "tough." In the reputation condition a reputation for rejecting low offers is, of course, valuable because it increases the likelihood of receiving high offers from the Proposers in future periods.

If the Responders understand that there is a pecuniary payoff from rejecting low offers in the reputation condition, one should observe higher acceptance thresholds in this condition. This is the prediction of the social preferences approach, which assumes that subjects derive utility from both their own pecuniary payoff and a fair payoff distribution. If, in contrast, subjects do not understand the logic of reputation formation and apply the same habits or cognitive heuristics to both conditions, one should observe no systematic differences in Responder behavior across conditions. Since the subjects participated in both conditions, it was possible to observe behavioral changes at the individual level. It turns out that the vast majority (slightly more than $80 \%$ ) of the Responders increase their acceptance thresholds in the reputation condition relative to the baseline condition. Moreover, not one subject reduces the acceptance threshold in the reputation condition relative to the baseline in a statistically significant way. ${ }^{7}$ This contradicts the hypothesis that subjects do not understand the difference between one-shot and repeated play.

The above experiment informs us about the proximate mechanism that drives Responder behavior in the ultimatum game. Whatever the exact proximate mechanisms turn out to be, a hypothesis that is based on the story that subjects do not really understand the difference between oneshot and repeated play seems to be wrong. A plausible alternative hypothesis is that Responders experience strong emotions when faced with a low offer and that these emotions trigger the rejections. For modeling purposes, behaviorally relevant emotions can be captured by appropriate formulations of the utility function. This is exactly what theories of social preferences do. 


\section{CONCLUDING REMARKS}

The empirical evidence shows that many people have inclinations to exhibit strongly reciprocal behavior. Strong reciprocity cannot be rationalized as an adaptive trait by the major prevailing evolutionary theories. The typical motives invoked by kin selection theory, by the theories of reciprocal altruism and indirect reciprocity, and by costly signaling theory cannot account for strong reciprocity. However, more recent evolutionary models like the ones by Gintis (2000), Bowles and Gintis (2001), Henrich and Boyd (2001), Sethi and Somananthan (1996, 2001a, 2001b), and multilevel selections theories of cultural evolution (Boyd and Richerson 1985) provide plausible evolutionary explanations of strong reciprocity.

Strong reciprocity constitutes a powerful constraint for potential cheaters that can generate almost universal cooperation in situations in which purely selfish behavior would cause a complete breakdown of cooperation. Moreover, our results on third-party punishment indicate that strong reciprocity is a, or perhaps the, key force in the enforcement of social norms. Once the presence of strongly reciprocal actors is taken into account, food-sharing and collective action norms are easy to explain. Strong reciprocity derives its power to fundamentally affect the aggregate outcomes of social interactions from the fact that it often changes the incentives for the selfish types in the population. In sequential interactions, for example, strong reciprocity constitutes an important cooperation incentive for purely self-interested first-movers. However, as the example of the simultaneously played PD shows, there are also interaction structures in which the selfish types induce the strongly reciprocal types to behave in a very noncooperative manner. This means that it is very important for social scientists to examine social interactions according to the objective possibilities of the selfish and reciprocal types to affect each other's behavior. In general, our experimental results show that the existence of strong reciprocators greatly improves the prospects for cooperation and norm enforcement. At a methodological level our results indicate that scientists who are interested in the evolution and the structure of human behavior have much to gain from the application of experimental methods. The recent successful experiments conducted by Henrich (2000) and others (see Henrich et al. 2001) suggest that the scientific returns from experimentation are particularly high in those disciplines (e.g., anthropology) where experimentation was absent or rare in the past.

This paper is part of a research project on strong reciprocity financed by the Network on Economic Environments and the Evolution of Individual Preferences and Social Norms of the MacArthur Foundation. 
Ernst Fehr is a professor of economics at the University of Zürich in Switzerland. $\mathrm{He}$ is on the editorial board of the Quarterly Journal of Economics, Games and Economic Behavior, the European Economic Review, the Journal of Socio-Economics, and Experimental Economics. Fehr studies the interplay among social preferences, social norms, and strategic interactions.

Urs Fischbacher has a position at the Institute for Empirical Research in Economics at the University of Zurich. He received his Ph.D. in mathematics at the University of Zurich. His research focuses on social preferences, the economics of social interactions, and game theoretic models of strong reciprocity.

Simon Gächter is a professor of economics at the University of St. Gallen in Switzerland. His primary research is on problems of incentive systems, contract enforcement, voluntary cooperation, and social norms.

\section{NOTES}

1. There is a large economic literature that tries to provide microfoundations for the existence of incomplete contracts. The empirical fact that many agreements contain an element of incompleteness is, however, undisputed. A prominent example is, of course, the labor contract.

2. For different evolutionary models of strong reciprocity see Bowles and Gintis (2001) and Sethi and Somananthan (1996, 2001a, 2001b).

3. In all experiments discussed in this paper completely anonymous strangers, who never learn the identities of their interaction partners, interact with each other. It is also not possible to acquire individual reputations for behaving in particular ways in these experiments.

4. It is important to stress that in the experimental instructions the terms rewarding and punishing were never used. The instructions were framed in neutral terms to avoid experimenter demand effects. The same holds for other experiments discussed in this paper.

5. If rationality and selfishness are not common knowledge, other equilibria exist in which there is cooperation and punishment during the early periods. However, for the final periods the "no cooperation-no punishment" prediction still holds.

6. A different interpretation is that people obey certain rules-such as, share money equally if you haven't earned it (which leads to equal-split offers in the ultimatum game; Güth 1995). A problem with the rule-based approach is that subjects do change their behavior in response to changes in payoffs, in predictable ways. For example, when the incremental payoff from defecting against a cooperator in a Prisoner's Dilemma is higher, people defect more often. When players' private benefits from the public good are higher, they contribute more. When the responder in the ultimatum game can no longer reject an offer, the proposers behave more selfishly on average. Any rule-based account must explain why the rules are bent by incentives, and such a theory will probably end up looking like a theory of social preferences, which explicitly weighs self-interest against other dimensions.

7. Note that constant acceptance thresholds across conditions are consistent with a social preferences approach, whereas a reduction in the acceptance thresh- 
old in the reputation condition would be inconsistent with this approach. If, for example, a subject rejects every offer below the equal split in the baseline condition, then this subject will in general not increase the acceptance threshold in the reputation condition.

\section{REFERENCES CITED}

Abbink, K., B. Irlenbusch, and E. Renner

2000 The Moonlighting Game: An Experimental Study on Reciprocity and Retribution. Journal of Economic Behavior and Organization 42:265-277.

Alexander, R. D.

1987 The Biology of Moral Systems. New York: Aldine de Gruyter.

Axelrod, R., and W. D. Hamilton

1981 The Evolution of Cooperation. Science 211:1390-1396.

Basu, Kaushik

1984 The Less Developed Economy. Oxford: Oxford University Press.

Berg, Joyce, John Dickhaut, and Kevin McCabe

1995 Trust, Reciprocity and Social History. Games and Economic Behavior 10:122142.

Bolle Friedel

1998 Rewarding Trust: An Experimental Study. Theory and Decision 45:85-100.

Bolton, Gary, and Rami Zwick

1995 Anonymity versus Punishment in Ultimatum Bargaining. Games and Economic Behavior 10:95-121.

Bolton, Gary E., and Axel Ockenfels

2000 A Theory of Equity, Reciprocity and Competition. American Economic Review 100:166-193.

Bowles, Sam, and Herbert Gintis

2001 The Evolution of Strong Reciprocity. Discussion Paper, University of Massachusetts at Amherst. Copy in the authors' possession.

Boyd, Robert, and Peter J. Richerson

1985 Culture and the Evolutionary Process. Chicago: University of Chicago Press.

1988 The Evolution of Reciprocity in Sizable Groups. Journal of Theoretical Biology 132:337-356.

Camerer, Colin F., and Richard $\mathrm{H}$. Thaler

1995 Ultimatums, Dictators and Manners. Journal of Economic Perspectives 9: 209-219.

Cameron, Lisa A.

1999 Raising the Stakes in the Ultimatum Game: Experimental Evidence from Indonesia. Economic Inquiry 37:47-59.

Charness, Gary

2000 Responsibility and Effort in an Experimental Labor Market. Journal of

Economic Behavior and Organization 42:375-384.

Charness, Gary, and Matthew Rabin

2000 Social Preferences: Some Simple Tests and a New Model. Unpublished ms., University of California at Berkeley. Copy in the authors' possession. 
Dufwenberg, Martin, and Georg Kirchsteiger

1998 A Theory of Sequential Reciprocity. Discussion Paper, Tilburg University. Copy in the authors' possession.

Falk, Armin, and Urs Fischbacher

1999 A Theory of Reciprocity. Institute for Empirical Research in Economics,

Working Paper No. 6. University of Zurich.

Fehr, Ernst, and Armin Falk

1999 Wage Rigidity in a Competitive Incomplete Contract Market. Journal of Political Economy 107:106-134.

Fehr, Ernst, and Urs Fischbacher

2001a Third Party Punishment. Institute for Empirical Research in Economics, Working Paper No. 106. University of Zürich.

2001b Retaliation and Reputation. Unpublished ms., Institute for Empirical

Research in Economics, University of Zürich.

Fehr, Ernst, and Simon Gächter

2000 Cooperation and Punishment in Public Goods Experiments. American Economic Review 90:980-994.

2002 Altruistic Punishment in Humans. Nature 415:137-140.

Fehr, Ernst, and Klaus M. Schmidt

1999 A Theory of Fairness, Competition and Co-operation. Quarterly Journal of Economics 114:817-868.

Fehr, Ernst, and Elena Tougareva

1995 Do High Monetary Stakes Remove Reciprocal Fairness? Experimental

Evidence from Russia. Unpublished ms., Institute for Empirical Economic Research, University of Zurich.

Fehr, Ernst, Georg Kirchsteiger, and Arno Riedl

1993 Does Fairness Prevent Market Clearing? An Experimental Investigation. Quarterly Journal of Economics 108:437-460.

1998 Gift Exchange and Reciprocity in Competitive Experimental Markets. European Economic Review 42:1-34.

Fehr, Ernst, Simon Gächter and Georg Kirchsteiger

1997 Reciprocity as a Contract Enforcement Device. Econometrica 65:833-860.

Friedman, James

1971 A Noncooperative Equilibrium for Supergames. Review of Economic Studies 38:1-12.

Fudenberg, Drew, and Eric Maskin

1986 The Folk Theorem in Repeated Games with Discounting or with Incom-

plete Information. Econometrica 54:533-556.

Gintis, Herbert

2000 Strong Reciprocity and Human Sociality. Journal of Theoretical Biology 206:169-179.

Gintis, Herbert, Eric Smith, and Sam Bowles

2001 Costly Signaling and Cooperation. Journal of Theoretical Biology, forthcoming.

Gächter, Simon, and Armin Falk

2001 Reputation and Reciprocity: Consequences for the Labour Relation. Institute for 
Empirical Research in Economics, Working Paper No. 19. University of

Zurich. (Also Scandinavian Journal of Economics, forthcoming)

Güth, Werner

1995 On the Construction of Preferred Choices: The Case of Ultimatum Pro-

posals. Discussion Paper, Economic Series No. 59. Berlin: Humboldt Univer-

sity.

Güth, Werner, Rolf Schmittberger, and Bernd Schwarze

1982 An Experimental Analysis of Ultimatium Bargaining. Journal of Economic

Behavior and Organization 3:367-388.

Hamilton, William D.

1964 Genetical Evolution of Social Behavior. Journal of Theoretical Biology 7:1-52.

Henrich, Joe

2000 Does Culture Matter in Economic Behavior? Ultimatum Game Experi-

ments among the Machiguenga of the Peruvian Amazon. American Economic Review 90:973-979.

Henrich, J., and R. Boyd

2001 Why People Punish Defectors: Weak Conformist Transmission Can Stabi-

lize Costly Enforcement of Norms in Cooperative Dilemmas. Journal of Theoretical Biology 208:79-89.

Henrich J., R. Boyd, S. Bowles, C. Camerer, E. Fehr, H. Gintis, and R. McElreath 2001 In Search of Homo economicus: Behavioral Experiments in 15 Small-Scale Societies. American Economic Review 91:73-79.

Hoffman, Elisabeth, Kevin McCabe, and Vernon Smith

1996 On Expectations and Monetary Stakes in Ultimatum Games. International Journal of Game Theory 25:289-301.

Levine, $\mathrm{D}$.

1998 Modeling Altruism and Spitefulness in Experiments. Review of Economic Dynamics 1:593-622.

McCabe, Kevin A., Stephen J. Rassenti, and Vernon L. Smith

1998 Reciprocity, Trust, and Payoff Privacy in Extensive Form Bargaining.

Games and Economic Behavior 24:10-24.

McCabe, K. A., Mary L. Rigdon, and V. L. Smith

2000 Positive Reciprocity and Intentions in Trust Games. Unpublished ms., University of Arizona, Tucson. Copy in the authors' possession.

Nowak, Martin, and Karl Sigmund

1998 Evolution of Indirect Reciprocity by Image Scoring. Nature 393:573-577.

Rabin, Matthew

1993 Incorporating Fairness into Game Theory and Economics. American Economic Review 83:1281-1302.

Roth, Alvin E.

1995 Bargaining Experiments. In Handbook of Experimental Economics, J. Kagel and A. Roth, eds. Pp. 253-348. Princeton: Princeton University Press.

Roth, Alvin E., Vesna Prasnikar, Masahiro Okuno-Fujiwara, and Shmuel Zamir 1991 Bargaining and Market Behavior in Jerusalem, Ljubljana, Pittsburgh, and Tokyo: An Experimental Study. American Economic Review 81:1068-1095. 
Sethi, R., and E. Somananthan

1996 The Evolution of Social Norms in Common Property Resource Use. American Economic Review 86:766-788.

2001a Understanding Reciprocity. Journal of Economic Behavior and Organization, forthcoming.

2001b Preference Evolution and Reciprocity. Journal of Economic Theory 97:273297.

Slonim, Robert, and Alvin E. Roth

1998 Financial Incentives and Learning in Ultimatum and Market Games: An Experiment in the Slovak Republic. Econometrica 65:569-596.

Sober, Elliott, and David Sloan Wilson

1998 Unto Others: The Evolution and Psychology of Unselfish Behavior. Cambridge: Harvard University Press.

Soltis, Joseph, Robert Boyd, and Peter Richerson

1995 Can Group-Functional Behaviors Evolve by Cultural Group Selection? An Empirical Test. Current Anthropology 36:473-495.

Trivers, R. L.

1971 The Evolution of Reciprocal Altruism. Quarterly Review of Biology 46: 35-57.

Zahavi, Amotz, and Avishay Zahavi

1997 The Handicap Principle: A Missing Piece of Darwin's Puzzle. New York: Oxford University Press. 